\title{
Complications of cerebral angiography for patients with mild carotid territory ischaemia being considered for carotid endarterectomy
}

\author{
Graeme J Hankey, Charles P Warlow, Andrew J Molyneux
}

\begin{abstract}
It is essential to image the carotid bifurcation adequately in patients with symptomatic carotid territory ischaemia if they are being considered for carotid endarterectomy. Optimal resolution is achieved by selective intraarterial contrast angiography which is an invasive procedure carrying some risk. The overall risk-benefit of carotid endarterectomy is currently being investigated in several large randomised trials in Europe and North America. Because cerebral angiography is a prerequisite for carotid endarterectomy, the risks of cerebral angiography will need to be added to those of surgery when considering whether carotid endarterectomy is effective in the management of these patients. This study evaluated prospectively 382 patients with symptomatically mild carotid ischaemia who had cerebral angiography to visualise a potentially resectable lesion at the carotid bifurcation. Complications followed 14 cerebral angiograms in 13 patients $(3 \cdot 4 \%)$; two complications were local $(0.5 \%)$, two systemic $(0.5 \%)$ and 10 were neurological $(2 \cdot 6 \%)$. The neurological complications were transient (TIA 1, generalised seizure 1) in two patients $(0.5 \%)$, reversible (stroke) in three $(0.8 \%)$ and permanent (stroke) in five patients $(1 \cdot 3 \%)$. There were no deaths. The significant risk factors for post angiographic stroke were (1) stroke before angiography compared with transient ischaemic attacks of the eye or brain and (2) the presence of $\geqslant 50 \%$ diameter stenosis of the symptomatic internal carotid artery; unfortunately it may be the latter patients who are most at risk of stroke as part of the natural history of their disease and therefore most in need of prophylactic carotid endarterectomy (which requires cerebral angiography). The absolute risk of post-angiographic stroke can be reduced by careful selection of patients for cerebral angiography using clinical evaluation and Duplex carotid ultrasound screening.
\end{abstract}

The utility of carotid endarterectomy in the management of patients with asymptomatic carotid artery stenosis, transient ischaemic attacks (TIA), and non-disabling ischaemic stroke in the carotid artery territory is currently being investigated in several large randomised trials in Europe and North America.

Before carotid endarterectomy is undertaken, the symptomatic carotid bifurcation must be adequately imaged. Although carotid endarterectomy is occasionally performed on the basis of the findings of Duplex carotid ultrasound ${ }^{1}$ or intravenous digital subtraction angiography (IV-DSA) studies alone, the images of the carotid bifurcation are clearly not optimal and almost all surgeons, in the United Kingdom, require angiographic demonstration of the carotid bifurcation by either conventional cerebral angiography or intra-arterial digital subtraction angiography (IA-DSA). ${ }^{23}$ These are invasive procedures, however, with an inherent risk that must be added to the surgical risk of carotid endarterectomy when making a decision on whether to recommend surgery. However, the degree of risk of cerebral angiography for patients with symptomatic carotid ischaemia is uncertain; reported complication rates vary from as low as zero to as high as $28 \%{ }^{4-7}$ These inconsistent results reflect the heterogeneity of the studies in terms of patient selection, study design, angiographic technique/expertise and the definition, assessment and interpretation of complications.

Almost all of the early studies were retrospective and therefore characterised by administrative problems (missing clinical notes or vital data) and methodological problems (inconsistent patient selection, nonstandard diagnostic and outcome criteria, variation in follow up frequency, and bias due to non-blind reviewers). Only eight prospective studies have addressed the complication rate of cerebral angiography for patients with ischaemic cerebrovascular disease and there have been no prospective studies of IADSA. ${ }^{7-14}$ The most methodologically sound studies aimed to ascertain the complication rate of cerebral angiography in general and not specifically in those patients with cerebrovascular disease..$^{912}$ Thus, overall, the eight studies accumulated 2227 cerebral angiograms in patients with cerebrovascular disease and the total neurological complication rate varied from $0 \cdot 7-11 \cdot 3 \%$ (overall average $4 \cdot 1 \%, 95 \%$ confidence interval [CI] 3.3-4.9\%). Neurological symptoms and signs were transient or reversible (resolving within seven days) in $0 \cdot 9-7 \cdot 1 \%$ (average $3.1 \%, 95 \% \mathrm{CI}$ : $2 \cdot 3-3.8 \%$ ) and permanent in $0-5.6 \%$ (average $1.0 \%, 95 \%$ CI: $0.6-1.5 \%)$. The overall mortality rate was $0.06 \%(95 \% \mathrm{CI}: 0-0 \cdot 18 \%){ }^{15}$ 
Should carotid endarterectomy be shown to improve stroke-free survival then the complication rate of cerebral angiography must be known for the various types of patients in whom carotid surgery may be indicated. This study was therefore prompted by the need to know the complication rate specifically for patients with symptomatically mild carotid territory ischaemia.

\section{Patients and methods \\ Patients}

Between 1977 and 1986, 615 patients with symptomatic carotid territory ischaemia were referred to one of us (CPW) and studied prospectively. The referral sources included the patients' general practitioners $(48 \%)$, the Oxford Eye Hospital ( $30 \%$ ), a vascular surgeon $\left(8^{\circ}{ }_{0}\right)$, a neurologist $(2 \%)$ and another consultant $(12 \%)$. The presenting disorders were transient ischaemic attack of the brain ( $n$ $\left.=243,40^{\circ}{ }_{0}\right)$ or eye $(n=171,28 \%)$, retinal infarction $(\mathrm{n}=106,17 \%)$, minor stroke ( $\mathrm{n}=$ $26,4^{\circ}{ }_{0}$ ) or non-disabling major stroke ( $n$ $\left.=69,11^{\circ}{ }_{0}\right)$. A previous stroke had occurred in 19 patients with transient ischaemia of the brain (TCIA), nine with transient ischaemia of the eye (amaurosis fugax) and seven with retinal infarction. The date of onset of the most recent symptomatic vascular event was recorded.

\section{Methods}

The reason for cerebral angiography was to image a potentially resectable vascular lesion at the symptomatic carotid bifurcation. Patients were only considered for angiography if they were potential surgical candidates from both a neurological and general medical point of view: relatively young in biological terms, systemically well and not uraemic. Patients were not screened for angiography (by cervical ausculation findings or carotid ultrasound). Angiography was performed by a consultant neuroradiologist or a radiology trainee under consultant supervision. The angiographic procedure was an arch study in $2^{\circ}{ }_{0}$ of procedures, direct carotid puncture, of just the symptomatic artery usually, in $31 \%$ : and selective catheterisation via the femoral route of the symptomatic and often asymptomatic carotid arteries in $67 \%$. The angiographic findings were recorded.

All patients had a neurological assessment by a neurologist (CPW) before angiography. Patients were observed during and immediately after angiography by the radiologist and upon return to the hospital ward by the neurology resident. The following day the patient was usually seen by a neurologist $(\mathrm{CPW})$. After hospital discharge all patients were followed prospectively by CPW until they either died, or the end of 1986.

All neurological events which were detected within 72 hours of angiography were recorded as complications of angiography. Complications were classified according to their duration as either transient (resolution of symptoms within 24 hours of onset), reversible (persisting beyond 24 hours but resolving within one week of onset) or permanent (persisting beyond one week) and according to their nature as either local (for example, haematoma, claudication worse, ischaemic foot), systemic (for example, allergic), neurological (focal neurological deficit) or death. The frequency of complications was expressed using the number of patients as the denominator. Disability was graded according to the modified Rankin scale $^{16}$ in those patients who suffered a disabling and permanent complication.

\section{Definitions}

Transient ischaemic attack ( $T I A$ ) : an acute loss of focal cerebral or ocular function with symptoms lasting less than 24 hours and which after adequate investigation was presumed to be due to embolic or thrombotic vascular disease. ${ }^{17}$ Neurological signs of no functional significance were acceptable thereafter.

Retinal infaction: an acute painless and persistent (beyond 24 hours) monocular loss of visual acuity or visual field with ophthalmoscopic findings of pallor of all or a section of the posterior pole of the retina. Additional findings included the presence of an afferent pupillary defect or embolic material in retinal arteries or arterioles of some patients or a cherry-red spot over the fovea in cases of central retinal artery occlusion.

Minor ischaemic stroke: an acute ischaemic disturbance of focal neurological function with symptoms lasting more than 24 hours and less than one week. Neurological signs of no functional significance were acceptable thereafter. Non-disabling major ischaemic stroke: an acute ischaemic disturbance of focal neurological function with symptoms lasting more than one week but with little or no residual disability (modified Rankin grade $0-2$ ). ${ }^{16}$

Hypertension: diastolic blood pressure $\geqslant 100$ $\mathrm{mm} \mathrm{Hg}$ (phase V) at presentation and/or known treated hypertension.

Cardiac arrhythmia: any previous or current supraventricular or ventricular arrhythmia documented by ECG recording.

Peripheral vascular disease: intermittent claudication in one or both limbs, ischaemic rest pain or past peripheral vascular surgery.

Diabetes mellitus: fasting venous plasma glucose level $\geqslant 8.0 \mathrm{mmol} / 1$ or random level $\geqslant$ $11.0 \mathrm{mmol} / 1$ and/or known treated diabetes.

Hypercholesterolaemia: plasma cholesterol $\geqslant$ $7.0 \mathrm{mmol} / 1$ and/or known treated hypercholesterolaemia.

\section{Results}

Cerebral angiography was performed in 382 of the 615 patients $(62 \%)$. The presenting disorder was transient ischaemic attack of the brain (carotid territory) in 152 patients or eye in 107 cases, retinal infarction in 59 , minor stroke in 15 , and major stroke in 49. A preceding stroke had occurred in 11 patients with TIA, nine with amaurosis fugax (AFx) and three with retinal infarction. 
Table 1 Patient details

\begin{tabular}{|c|c|c|c|c|c|c|c|c|c|c|c|}
\hline \multirow[b]{2}{*}{$\begin{array}{l}\text { Case } \\
\text { No }\end{array}$} & \multirow[b]{2}{*}{ Age } & \multirow[b]{2}{*}{ Sex } & \multirow[b]{2}{*}{ Diagnosis } & \multirow{2}{*}{$\begin{array}{l}\text { No in } \\
\text { last } \\
6 \text { weeks }\end{array}$} & \multirow[b]{2}{*}{$\begin{array}{l}\text { Past } \\
\text { history }\end{array}$} & \multicolumn{5}{|c|}{ Complications } & \multirow[b]{2}{*}{$\begin{array}{l}\text { Angio } \\
\text { findings }\end{array}$} \\
\hline & & & & & & Local & Systemic & Transient & $\begin{array}{l}\text { Neurological } \\
\text { reversible }\end{array}$ & Permanent & \\
\hline 1 & 73 & F & $\begin{array}{l}\text { (L) lacunar } \\
\text { stroke }\end{array}$ & 1 & Hypertension & $\begin{array}{l}\text { CCA } \\
\text { dissection }\end{array}$ & & & & & $\begin{array}{l}\text { No carotid } \\
\text { stenosis or }\end{array}$ \\
\hline 2 & 67 & $M$ & (L) A Fx & 5 & $\begin{array}{l}\text { IHD } \\
\text { Hypertension } \\
\text { PVD } \\
\text { Ex-smoker }\end{array}$ & $\begin{array}{l}\text { Rest pain } \\
\text { ipsilat. leg }\end{array}$ & & & & & $\begin{array}{l}\text { (L) ICA origin: } \\
\text { 98\% stenosis } \\
\text { (R) ICA origin: } \\
50 \% \text { stenosis }\end{array}$ \\
\hline 3 & 52 & $M$ & (L) TIA & 1 & $\begin{array}{l}\text { IHD } \\
\text { Hypertension } \\
\text { PVD } \\
\text { Smoker }\end{array}$ & & $\begin{array}{l}\text { Glaucoma } \\
\text { (atropine) }\end{array}$ & & & & $\begin{array}{l}\text { (L) ICA origin: } \\
50 \% \text { stenosis }\end{array}$ \\
\hline 4 & 76 & $M$ & (R) TIA & 8 & & & $\begin{array}{l}\text { Angio no } 1 \\
\text { HR } \downarrow \text {, BP } \downarrow \\
\text { TIA: } \\
\text { (R) hemisph. }\end{array}$ & & $\begin{array}{l}\text { Angio no } 2 \\
\text { Stroke: } \\
\text { (R) hemisphere }\end{array}$ & & $\begin{array}{l}\text { (R) ICA origin: } \\
\text { 50\% stenosis } \\
\text { (L) ICA: } 10 \% \\
\text { stenosis }\end{array}$ \\
\hline 5 & 58 & $M$ & (R) TIA & 5 & $\begin{array}{l}\text { Epilepsy: } \\
\text { nocturnal }\end{array}$ & & & $\begin{array}{l}\text { Seizure: } \\
\text { gen ton/clon. }\end{array}$ & & & Normal \\
\hline 6 & 64 & $M$ & (R) TIA & 4 & $\begin{array}{l}\text { Hypertension } \\
\text { Ex-smoker }\end{array}$ & & & $\begin{array}{l}\text { TIA: (L) hand } \\
\text { tingling: minutes }\end{array}$ & & & $\begin{array}{l}\text { (R) ICA: } \\
20 \% \text { stenosis }\end{array}$ \\
\hline 7 & 61 & $\mathbf{M}$ & $\begin{array}{l}\text { (R) Stroke } \\
\text { Rankin 1 }\end{array}$ & 1 & & & & & Stroke: (R) hem. & & $\begin{array}{l}\text { (R) ICA origin: } \\
98 \% \text { stenosis }\end{array}$ \\
\hline 8 & 51 & $M$ & $\begin{array}{l}\text { (L) Stroke } \\
\text { Rankin } 2\end{array}$ & 1 & $\begin{array}{l}\text { M. Infarct } \\
\text { Ex-smoker }\end{array}$ & & & & $\begin{array}{l}\text { Stroke: } \\
\text { (L) MCA infarct: }\end{array}$ & & $\begin{array}{l}\text { (L) ICA: } \\
\text { occluded } \\
\text { (R) ICA origin: }\end{array}$ \\
\hline 9 & 59 & $M$ & (R) BRAO & 1 & Ex-smoker & & & & & $\begin{array}{l}\text { Stroke: } \\
\text { (L) hand } \\
\text { clumsy } \\
\text { Rankin gr } 1\end{array}$ & $\begin{array}{l}\text { (R) ICA origin: } \\
65 \% \text { stenosis } \\
\text { and ulcer } \\
\text { (L) ICA: } \\
45 \% \text { stenosis }\end{array}$ \\
\hline 10 & 71 & $M$ & (R) TIA & 5 & $\begin{array}{l}\text { PVD } \\
\text { Ex-smoker }\end{array}$ & & & & & $\begin{array}{l}\text { Stroke: } \\
\text { (R) pariet.- } \\
\text { occip. } \\
\text { Rankin gr } 2\end{array}$ & $\begin{array}{l}\text { (R) ICA origin: } \\
\text { 62\% stenosis } \\
\text { (R) siphon: } 30 \% \\
\text { (L) ICA: } 10 \%\end{array}$ \\
\hline 11 & 59 & $M$ & (R) CRAO & 1 & $\begin{array}{l}\text { Hypertension } \\
\text { Ex-smoker }\end{array}$ & & & & & $\begin{array}{l}\text { Stroke: } \\
\text { (R) MCA } \\
\text { infarct } \\
\text { Rankin gr } 4\end{array}$ & $\begin{array}{l}\text { (R) ICA origin: } \\
\text { 95\% stenosis } \\
\text { (L) ICA origin: } \\
70 \% \text { stenosis. }\end{array}$ \\
\hline 12 & 67 & $M$ & $\begin{array}{l}\text { (L) Stroke } \\
\text { Rankin 1 }\end{array}$ & 1 & Pipe smoker & & & & & $\begin{array}{l}\text { Stroke: } \\
\text { (L) MCA } \\
\text { infarct } \\
\text { Rankin gr } 2\end{array}$ & $\begin{array}{l}\text { (L) ICA origin: } \\
50 \% \text { stenosis and } \\
\text { ulceration } \\
\text { (R) ICA origin: } \\
23 \% \text { stenosis }\end{array}$ \\
\hline 13 & 23 & $M$ & $\begin{array}{l}\text { (L) Stroke } \\
\text { Rankin } 3\end{array}$ & 1 & $\begin{array}{l}\text { IDDM } \\
\text { Smoker } \\
\text { Strong } \\
\text { FH CVD }\end{array}$ & & & & & $\begin{array}{l}\text { Stroke: } \\
\text { (R) MCA } \\
\text { infarct } \\
\text { Rankin gr } 3\end{array}$ & $\begin{array}{l}\text { (L) MCA } \\
\text { stenosis } \\
\text { (L) MCA branch } \\
\text { occlusion } \\
\text { (R) MCA } \\
\text { stenosis }\end{array}$ \\
\hline
\end{tabular}

$\star(L)$ and $(R)$ refers to the symptomatic carotid artery, side of the brain or eye

TIA: transient ischaemic attack

AFx: amaurosis fugax

CRAO/BRAO: central/branch retinal artery occlusion

IHD: ischaemic heart disease

PVD: peripheral vascular disease

IDDM: insulin-dependent diabetes mellitus

$\mathrm{CCA}=$ common carotid artery

$\mathrm{ICA}=$ internal carotid artery

The median age was 61 years (range 6-76 years) with a male predominance $(72 \%)$. Risk factors for vascular disease were common: current smoking (48\%), hypertension ( $44 \%$ ) hypercholesterolaemia $(43 \%)$, heart disease: ischaemic + /or valvular $(36 \%)$, cardiac arrhythmia $(20 \%)$, peripheral vascular disease $(18 \%)$ and diabetes mellitus $(5 \%)$. A previous history of migraine was present in $19 \%$ of patients (common $3 \%$, classic $16 \%$ ) and $64 \%$ of women were post-menopausal.

Treatment was continued in many cases or instituted after clinical evaluation, frequently before angiography; aspirin in $51 \%$, aspirin and dipyridamole in $1 \%$, anticoagulants in $2 \%$ and no antithrombotic medications in $46 \%$. Carotid endarterectomy was subsequently undertaken in 73 cases (19\%) and another 27 $(7 \%)$ were randomised to no-surgery in the European Carotid Surgery Trial.

Angiography adequately imaged 542 internal carotid arteries (right 281, left 261). Variable degree of stenosis were present at the origin of
$83 \%$ of internal carotid arteries and ulceration was detected in $30 \%$. Carotid siphon disease was present in $20 \%$ of internal carotid arteries.

Complications followed 14 cerebral angiograms in 13 patients $(3.4 \%)$. Two complications were local $(0.5 \%)$, two systemic $(0.5 \%)$ and 10 were neurological $(2 \cdot 6 \%)$ (table 1$)$. There were no deaths.

Local complications $(\mathrm{n}=2)$ (table 1 )

One patient developed a local asymptomatic dissection of the posterior wall of the common carotid artery at the site of direct carotid puncture. Another patient who suffered intermittent claudication developed severe rest pain in the leg following ipsilateral femoral artery puncture.

Systemic complications $(\mathrm{n}=2)$

Following pre-medication with a preparation containing atropine one patient developed acute closed angle glaucoma which responded to topical pilocarpine eye drops. Bradycardia and hypotension occurred immediately following contrast injection in another patient pre- 
Table 2 Post-angiographic stroke rate for symptomatic carotid ischaemia

\begin{tabular}{|c|c|c|c|c|c|c|c|c|}
\hline \multirow[b]{3}{*}{ Diagnosis } & \multirow[b]{3}{*}{ Patients } & \multicolumn{6}{|c|}{ Post-angiogram stroke } & \multirow[b]{3}{*}{$(95 \% C I)$} \\
\hline & & \multicolumn{2}{|c|}{ Reversible } & \multicolumn{2}{|c|}{ Permanent } & \multicolumn{2}{|c|}{ Total } & \\
\hline & & No & $\%$ & No & $\%$ & No & $\%$ & \\
\hline $\begin{array}{l}\text { TIA brain + /or eye } \\
\text { Retinal Infarct } \\
\text { Stroke } \\
\text { Total }\end{array}$ & $\begin{array}{r}259 \\
59 \\
64 \\
382\end{array}$ & $\begin{array}{l}1 \\
0 \\
2 \\
3\end{array}$ & 0.8 & $\begin{array}{l}1 \\
2 \\
2 \\
5\end{array}$ & $1 \cdot 3$ & $\begin{array}{l}2 \\
2 \\
4 \\
8\end{array}$ & $\begin{array}{l}0 \cdot 8 \\
3 \cdot 4 \\
6 \cdot 2 \\
2 \cdot 1\end{array}$ & $\begin{array}{l}(0-1 \cdot 8) \\
(0-8 \cdot 0) \\
(0 \cdot 3-12 \cdot 1) \\
(0 \cdot 7-3 \cdot 5)\end{array}$ \\
\hline
\end{tabular}

cipitating left sided weakness that was transient, resolving with restoration of the systemic blood pressure to normal.

Neurological complications $(\mathrm{n}=10)$ (tables 1 and 2)

Neurological complications were transient in two cases, reversible in three and permanent in five cases.

A generalised tonic/clonic seizure occurred within hours of angiography in a patient who had a 10 year history of sleep-associated seizures and who had recently withdrawn phenobarbital treatment while continuing phenytoin. In accordance with conventional criteria, adopted for this study, this was recorded as an angiographic complication. Another patient developed transient tingling in the left hand during selective injection of the right carotid artery with contrast medium.

Angiography was complicated by a stroke in eight patients $(2 \cdot 1 \% ; 95 \%$ confidence interval $(0 \cdot 7-3.5 \%)$. The neurological deficit completely resolved within seven days in three cases but persisted beyond this time in five. No deaths occurred. Three of those with permanent deficits were mildly disabled at seven days after angiography (Rankin grade 1 or 2), one was moderately disabled (grade 3 ) and one was severely disabled (grade 4).

All eight patients who suffered a postangiographic stroke were men and the mean age was 58 years (range 23-76). The prevalence of risk factors for vascular disease did not differ significantly from those in whom angiography was not complicated by stroke.

Post angiographic stroke occurred in two of the 152 patients who presented with TIA $(1.3 \%)$, none of the 107 patients with $A F x$, two of the 59 with retinal infarction (3.4\%) and four of the 64 who presented following a stroke $(6 \cdot 2 \%)$. The two patients with TIA and post angiographic stroke had been experiencing frequent (weekly) TIAs before angiography. The rate of post-angiographic stroke was significantly higher in those patients who had suffered a stroke before cerebral angiography than those who were being investigated for transient ischaemic attacks of the eye or brain ( $p=0.015$, Fisher's exact test). More noteworthy, however, was the presence of "significant" ( $\geqslant 50 \%$ diameter stenosis) disease at the origin of the symptomatic internal carotid artery (ICA) in seven of the eight patients $(88 \%)$ who had a post angiographic stroke compared with 120 of the 374 patients $(32 \%)$ who did not (Chi square with Yates correction $=8 \cdot 5$, odds ratio $(\mathrm{OR})=14 \cdot 8,95 \%$ confidence interval (CI) of $O R=2 \cdot 4-91)$. The eighth patient had severe stenosis of the origin of the symptomatic middle cerebral artery. Symptomatic ICA stenosis $\geqslant 95 \%$ was present in three of the eight patients who had a stroke after angiography in contrast to only 33 of the 374 who did not (Chi square with Yates correction $=4 \cdot 6, \mathrm{OR}=6 \cdot 2,95 \% \mathrm{CI}$ of $\mathrm{OR}=1 \cdot 2$ 33).

\section{Discussion}

The total neurological complication rate of cerebral angiography for these 382 patients with symptomatic carotid territory ischaemia who were being considered for carotid endarterectomy was $2 \cdot 6 \%(95 \% \mathrm{CI}: 1 \cdot 0-4 \cdot 2 \%)$. Neurological complications were transient or reversible in five $(1.3 \%)$ and permanent in five patients $(1 \cdot 3 \%, 95 \% \mathrm{CI}: 0 \cdot 2-2 \cdot 4 \%)$. This result falls within the $95 \%$ confidence interval of the overall permanent neurological complication rate of the other eight prospective studies. ${ }^{7-15}$

Stroke was the major complication and constituted three of the reversible events and all of the permanent events $(2 \cdot 1 \%)$. Previous studies have postulated several risk factors for postangiographic stroke. These include: old age; ${ }^{12}$ general ill health and systemic disease ${ }^{14}$; cerebrovascular disease as the indication for cerebral angiography as opposed to other indications such as cerebral aneurysm, tumour or arteriovenous malformation ${ }^{12}$; frequent TIAs and recent stroke; stroke-in-evolution ${ }^{18}$; carotid artery disease ${ }^{131819}$; cerebral angiography performed by inexperienced radiology trainees ${ }^{13}$; use of a greater volume of contrast, ${ }^{12}$ a greater number of catheters and catheter exchanges, ${ }^{912}$ and longer duration procedures. $^{12}$

The patients who suffered a post-angiogram stroke in our series were of mean age 58 years (range 23-76) which was younger but not significantly different from the other patients having angiography. All eight patients were male and were considered medically fit for angiography and carotid surgery, should it have been appropriate. Frequent TIAs preceded cerebral angiography in both TIA patients who subsequently suffered stroke. No patient with stroke-in-evolution was subjected to cerebral angiography but stroke onset preceded cerebral angiography by less than six weeks in the four previous stroke cases.

Post-angiographic stroke occurred in a significantly greater proportion of patients who had suffered a stroke $(6 \cdot 2 \%)$ before cerebral angiography than those who had transient ischaemic attacks of the eye or brain $(0.8 \%)$. Unfortunately, almost all previous studies have 
not categorised both the indications for cerebral angiography and the post-angiographic complications according to whether the patients had prior TIAs or stroke. Frequently this information was only available for one or the other. The only prospective study to have done so was that of McIvor et al ${ }^{13}$ which recorded the total neurological complication rates (not just stroke rates) and found that they were almost equal for patients with prior TIAs $(13 \cdot 1 \%)$ and stroke $(12 \cdot 4 \%)$. (OR $=0.94,95 \%$ CI of the OR $=0 \cdot 2-5 \cdot 3)$. In our series, the total neurological complication rate for patients with prior TIAs was $1.6 \%$ and for stroke $6.7 \%(\mathrm{OR}=4.2,95 \% \mathrm{CI}$ of the $\mathrm{OR}=$ 0.8-22), whereas for the post angiographic stroke rate there was a statistically significant difference, albeit with wide confidence intervals $(\mathrm{OR}=8 \cdot 6,95 \% \mathrm{CI}$ of the $\mathrm{OR}=1 \cdot 5-$ $5 \cdot 0)$.

The prevalence of internal carotid artery diameter stenosis of $\geqslant 50 \%$ in all but one patient who had a post-angiogram stroke was the most striking and significant predictor of this complication but the $95 \%$ confidence interval of the odds ratio was very wide due to the small total number with complications. It is remarkable that only one of the prospective studies looked for a potential correlation between the severity of internal carotid artery (ICA) disease and the complication rate of cerebral angiography, since this relationship is commonly assumed. McIvor et al ${ }^{13}$ studied 230 cerebral angiograms in 229 patients with symptomatic cerebrovascular disease and found that 26 patients $(11 \cdot 3 \%)$ suffered a post-angiographic neurological complication. No statistically significant correlation was present between ICA disease and total neurological complication rate (for ICA stenosis $>85 \%$ : OR = $1 \cdot 1,95 \%$ CI of the OR: $0 \cdot 1-10$; for ICA stenosis $>50 \%$ : OR $=0.77,95 \%$ CI of the OR: $0 \cdot 2-2 \cdot 9)$. The neurological deficits were transient in seven, reversible in six, and permanent in $13(5.7 \%)$. Of the five patients who suffered a major disabling stroke, the symptomatic ICA was occluded in two, $70 \%$ stenosed in one and the other two showed $40 \%$ and $20^{\circ}$ o stenosis respectively. Although these figures suggest an association between ICA stenosis and post angiographic disabling stroke, the numbers were small.

In another prospective study, Earnest et al evaluated 637 cerebral angiograms for patients with cerebrovascular disease and, although the angiographic findings were not collected, 297 of these patients $(47 \%)$ had a preangiographic evaluation by oculopneumoplethysmography and bidirectional Doppler sonography. A pressure-significant lesion and/or abnormal flow was present in the carotid circulation of $54 \%$ of these examinations $(n=160) .{ }^{9}$ Such an abnormality was of no value in predicting an increased risk for neurological complications in this group but of course less than half the patients were investigated and the degree of ICA stenosis determined by these non-invasive methods may have been imprecise. ${ }^{9}$ Several retrospective studies have addressed the potential influence of ICA disease on the compli- cation rate of cerebral angiography but, as expected from the variable methodology of the studies, the conclusions also vary.

Faught et al examined retrospectively the records of 147 patients having cerebral angiography to evaluate a thrombotic stroke or TIA and found that neurological complications occurred in $18(12 \cdot 2 \%)$, of which 10 were transient $(7 \%)$ and eight permanent $(5 \cdot 2 \%){ }^{19}$ Severe ICA stenosis ( $>90 \%$ ) was present in eight of the 18 patients with complications $(39 \%)$ compared with 15 of the $129(12 \%)$ who had no complications (Chi square with Yates correction $=6 \cdot 2, \mathrm{OR}=3 \cdot 8,95 \% \mathrm{CI}=1 \cdot 3$ $11, \mathrm{p}=0.03)$. It was not stated what proportion of the complications in those with severe ICA stenosis were transient or permanent. Theodotou et $a l^{18}$ reviewed the cerebral angiograms of 159 patients who had carotid endarterectomy. All 159 patients had at least $70 \%$ stenosis of one carotid artery and 16 had bilateral ICA stenosis $>90 \%$. Neurological complications, all of which were transient, occurred in five patients $(3.1 \%)$, three of whom had unilateral ICA stenosis of $>90 \%$ and two had bilateral ICA stenosis $>90 \%$. The prevalence of severe ICA stenosis $(>90 \%)$ in the patients without complications was not stated. Eisenberg $e t$ al studied the records of 85 patients with ICA stenosis $>90 \%$ and no complications were recorded but the angiographic complication rate of those with $<90 \%$ ICA stenosis was not addressed. ${ }^{20}$

It is difficult to draw any reasonable conclusion from these data because of the variable definitions and methodology between each study and the small number of complications. The only information that is common to these studies which correlates the angiographic complication rate with the angiographic findings and is available for comparison is the total (not just permanent, and including more than strokes), neurological complication rate for severe (85-95\%) ICA stenosis. (There are no other data on the stroke rate for patients with ICA stenosis $>50 \%$ with which our findings can be compared). The pooled estimate of the odds ratio, $^{21}{ }^{22}$ for any post-angiographic

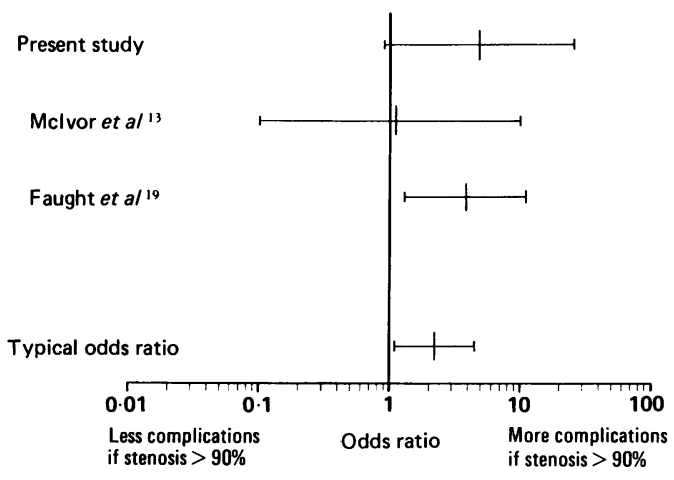

Figure Overview of the total neurological complication rate of cerebral angiography for patients with symptomatic carotid ischaemia and ipsilateral internal carotid artery diameter stenosis of approximately $90 \%$. Each study result is expressed as an odds ratio (vertical central bar) and $95^{\circ}$ confidence interval (horizontal line). The risk of post-angiographic stroke for patients with ICA stenosis $\geqslant 50^{\circ}$ o was not available in two previous studies. ${ }^{13} 19$ 
neurological complication is $2 \cdot 2$ (95\% confidence interval of the OR: $1 \cdot 1-4 \cdot 5)$ if the angiogram shows severe stenosis ( $>$ approximately $90^{\circ}$ ) of the symptomatic ICA as compared with milder degrees of ICA stenosis. Although far from complete, this information is sufficient to suggest that severe stenosis of the symptomatic ICA is a potentially important risk factor for post-angiographic stroke (fig). Unfortunately, it is these patients who are probably also at greatest risk of stroke as part of the natural history of their disease ${ }^{23}$ and therefore are those who may be in greatest need for carotid surgery and therefore cerebral angiography.

In this study 382 of the 615 patients $(62 \%)$ with symptomatic carotid territory ischaemia were considered to be potentially suitable candidates for carotid endarterectomy on clinical grounds. Carotid ultrasound facilities were not available before screening and so all potential candidates for carotid endarterectomy were referred for cerebral angiography on clinical grounds. However, after cerebral angiography only 100 of the 382 patients $\left(26^{\circ}{ }_{0}\right)$ were considered suitable for carotid endarterectomy or randomisation into the European Carotid Surgery Trial, (once the latter had started). Therefore, to generate 100 carotid endarterectomies, 382 patients had cerebral angiography and eight post-angiographic strokes resulted, of which five were permanently disabling. So, before surgery started the complication rate was $8^{\circ}{ }_{0}(8 / 100)$ for any stroke and $5{ }^{\circ}{ }_{0}(5 / 100)$ for permanent stroke. These figures must then be added to the peri-operative complication rate. Such an analysis highlights the importance of accurately screening and selecting patients for cerebral angiography by careful clinical and ultrasonographic evaluation. Otherwise, if the patient is not a suitable candidate for carotid endarterectomy then cerebral angiography will have been performed unnecessarily, exposing the patient to an unnecessary risk.

Radiological expertise and facilities were fairly uniform throughout this study but the access route to the arterial system varied between direct carotid puncture at the beginning of the study and selective carotid catheterisation via the femoral route later in the study. The catheter technique used was consistent throughout with a USCI Simmons 3 (Sidewinder) catheter. This does not require guide wire manipulation to catheterise the brachiocephalic vessels. This was the only catheter required in the vast majority of patients. In fact, only one patient developed a complication following direct carotid puncture which was a local asymptomatic carotid dissection (case 1, table 2).

The risk of cerebral angiography naturally varies from one medical institution to another, in much the same way as it does for carotid endarterectomy, mainly because of differences in patient selection and radiological facilities and expertise. The collective results from this study and those previously published cannot really be generalised to all medical centres but only used as an approximate guide. All medical institutions performing cerebral angiography for symptomatic carotid territory ischaemia need to monitor their own results and complications of cerebral angiography, in much the same manner as for carotid endarterectomy, by means of a formal but practical ongoing audit. ${ }^{15}$

If carotid endarterectomy is shown to be effective in the management of certain patients with symptomatically mild carotid territory ischaemia then optimal imaging of the carotid circulation will be required with the lowest possible risk and cost in a very large number of patients. Conventional selective intra-arterial cerebral angiography is the most accurate and widely used modality at present, but IA-DSA is gaining wider acceptance. Before proceeding to cerebral angiography, patients considered clinically to be potential surgical candidates (that is, reversible symptomatic carotid ischaemia perhaps) should undergo non-invasive Duplex carotid ultrasound screening to identify those patients with minimal or no carotid disease who do not then require cerebral angiography. This will reduce considerably the absolute numbers of patients having cerebral angiography (denominator) but will probably only reduce marginally the absolute number of post-angiographic complications (numerator). As a result, the relative (percentage) complication rate of cerebral angiography (numerator/denominator) will probably rise because angiography will only be performed on those patients with "significant" carotid disease, who are unfortunately also those who appear to be at highest risk of postangiographic stroke.

In conclusion, for patients with symptomatic carotid territory ischaemia who undergo cerebral angiography as a pre-operative investigation for carotid endarterectomy, the risk of suffering a permanent disability due to stroke is of the order of $1{ }^{\circ}{ }_{0} .{ }^{15}$ This figure will need to be considered when balancing the benefits and risks of adding surgical to medical therapy in the management of symptomatic carotid territory ischaemia. Meanwhile, it would seem logical to assume that the complications of cerebral angiography can be reduced if patients are selected carefully for this procedure. The selection criteria include: physiologically younger patients who are systemically well, not uraemic, and neurologically stable who have definite symptoms of carotid ischaemia, and who on Duplex screening have a potentially operable lesion at the symptomatic carotid bifurcation. The risk of angiography will also be reduced if arch and/or selective cerebral angiography is performed by an experienced neuroradiologist using a transfemoral approach with small catheters, minimal quantities on non-ionic contrast medium and as few catheter exchanges as possible in the shortest time.

We thank Drs P Anslow and P Sheldon, radiologists, Radcliffe Infirmary, Oxford, for their contribution to the cerebral Infirmary, Oxford, for their contribution to
angiography of many of the patients in this study.

1 Ricotta JJ, Holen J, Schenk E, et al. Is routine angiography necessary prior to carotid endarterectomy? J Vasc Surg 
1984;1:96-102.

2 Cebul RD, Paulus RA. The failure of intravenous digital subtraction angiography in replacing carotid arteriography. Ann Int Med 1986;104:572-4.

3 Murie JA, Morris PJ. Carotid endarterectomy in Great Britain and Ireland. Br J Surg 1986;73:867-70.

4 Muller R, Greitz I, Lilieqvist B, et al. Aortocervical angiography in occlusive cerebrovascular disease. Neurology 1964;14:136-46.

5 Burrows EH, Marshall J. Angiographic investigation of patients with transient ischaemic attacks. J Neurol Neurosurg Psychiatry 1965;28:533-9.

6 Siguerra EB. Cerebral angiography in the elderly patient. Geriatrics 1965;20:835-40.

7 Kerber CW, Cromwell LD, Drayer BP, Bank WO. Cerebral ischaemia. I. Current angiographic techniques, complicaischaemia. 1. Current angiographic techniques, complica-

8 Skalpe IO, Anke IM. Complications in cerebral angiography: a comparison between the non-ionic contras medium iohexol and meglumine metrizoate (Isopaque Cerebral). Neuroradiology 1983;25:157-60.

9 Earnest F, Forbes G, Sandok BA, et al. Complications of cerebral angiography: prospective assessment of risk. $A J R$ 1984;142:247-53.

10 Ball JB, Lukin RR, Tomsick TA, Chambers A. Complications of intravenous digital subtraction angiography. Arch Neurol 1985;42:969-72.

11 Gasparini M, Arosio M, Galbiati N, et al. Neurological complications of cerebral angiography. Ital J Neurol Sci complication

12 Dion JE, Gates PC, Fox AJ, Barnett HJM, Blom RJ. Clinical events following neuroangiography: a prospective study. Stroke 1987;18.997-1004.

13 McIvor J, Steiner TJ, Perkin GD, Greenhalgh RM, Clifford
Rose F. Neurological morbidity of arch and carotid arteriography in cerouscular disease. The influence of arteriography in cerebrovascular disease. The influence of contrast

14 Aaron JO, Hesselink JR, Oot R, Jones RL, Davis KR, Taveras JM. Complications of intravenous DSA performed for carotid artery disease: a prospective study. Radiology 1984;153:675-8.

15 Hankey GJ, Warlow CP, Sellar RJ. Cerebral angiographic: risk in mild cerebrovascular disease. Stroke; 21:209-22.

16 Bamford JM, Sandercock PAG, Warlow CP, Slattery Interobserver agreement for the assessment of handicap in stroke patients. Stroke 1989;20:828.

17 Warlow CP, Morris PJ. Introduction. In: Warlow CP, Morris PJ, eds. Transient ischaemic attacks. New York: Marcel Decker, 1982:7-11.

18 Theodotou BC, Whaley R, Mahaley MS. Complications following transfemoral cerebral angiography for cerebral ischaemia. Report of 159 angiograms and correlation with ischaemia. Report of 159 angiograms and
surgical risk. Surg Neurol 1987;28:90-2.

19 Faught E, Trader SD, Hanna GR. Cerebral complications of angiography for transient ischaemia and stroke: prediction of risk. Neurology 1979;29:4-15.

20 Eisenberg RL, Bank WO, Hedgcock MW. Neurologic complications of angiography in patients with critical stenosis of the carotid artery. Neurology 1980;30:892-5.

21 Antiplatelet trialists' collaboration: secondary prevention of vascular disease by prolonged antiplatelet treatment. $\mathrm{Br}$ Med J 1988;296:320-31.

22 Morris JA, Gardner MJ. Calculating confidence intervals for relative risks (odds ratios) and standardised ratios and relative risks (odds ratios) and

23 Chambers BR, Norris JW. Outcome in patients with asymptomatic neck bruits. New Eng J Med 1986;315:860-5. 